University of New Hampshire

University of New Hampshire Scholars' Repository

Faculty Publications

6-30-2008

\title{
The Western Arctic Linkage Experiment (WALE): Overview and Synthesis
}

\author{
A. D. McGuire \\ University of Alaska Fairbanks \\ J. E. Walsh \\ University of Alaska Fairbanks \\ J. S. Kimball \\ University of Montana \\ J. S. Clein \\ University of Alaska Fairbanks \\ S. E. Euskirchen \\ University of Alaska Fairbanks
}

See next page for additional authors

Follow this and additional works at: https://scholars.unh.edu/faculty_pubs

Comments

This is an article published by American Meteorological Society in Earth Interactions in 2008, available online:

https://dx.doi.org/10.1175/2008EI239.1

\section{Recommended Citation}

Maslanik, R.B. Lammers, M. Rawlins, C. Vorosmarty, T.S. Rupp, W. Wu, M. Calef (2008) The Western Arctic Linkage Experiment (WALE): Overview and Synthesis, Earth Interactions, 12, paper 7, 13 pages, doi:10.1175/2008EI239.1.

This Article is brought to you for free and open access by University of New Hampshire Scholars' Repository. It has been accepted for inclusion in Faculty Publications by an authorized administrator of University of New Hampshire Scholars' Repository. For more information, please contact Scholarly.Communication@unh.edu. 


\section{Authors}

A. D. McGuire, J. E. Walsh, J. S. Kimball, J. S. Clein, S. E. Euskirchen, S. Drobot, U. C. Herzfeld, J. Maslanik, Richard B. Lammers, M. A. Rawlins, and J. Maslanik 


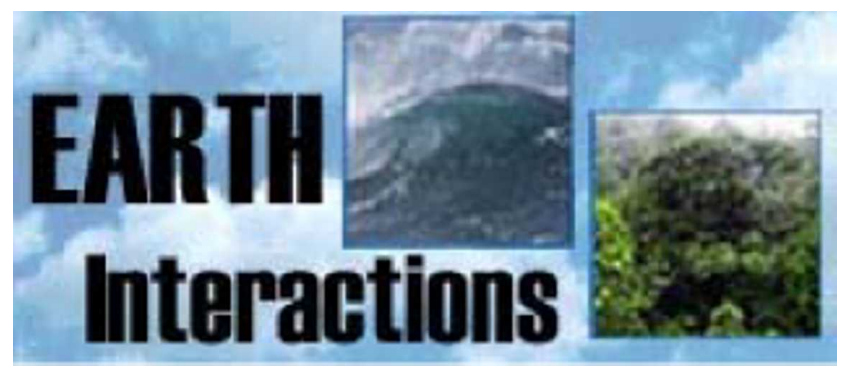

Copyright (c) 2008, Paper 12-007; 5,508 words, 2 Figures, 0 Animations, 0 Tables. http://EarthInteractions.org

\section{The Western Arctic Linkage Experiment (WALE): Overview and Synthesis}

\section{A. D. McGuire*}

U.S. Geological Survey, Alaska Cooperative Fish and Wildlife Research Unit, University of Alaska Fairbanks, Fairbanks, Alaska

\section{J. E. Walsh}

International Arctic Research Center, University of Alaska Fairbanks, Fairbanks, Alaska

\section{J. S. Kimball}

Flathead Lake Biological Station, Division of Biological Sciences, University of Montana, Polson, Montana

\section{J. S. Clein and S. E. Euskirchen}

Institute of Arctic Biology, University of Alaska Fairbanks, Fairbanks, Alaska

\section{S. Drobot, U. C. Herzfeld, and J. Maslanik}

University of Colorado, Boulder, Colorado

* Corresponding author address: A. D. McGuire, 214 Irving I Building, University of Alaska Fairbanks, Fairbanks, AK 99775.

E-mail address: ffadm@uaf.edu 
Earth Interactions - Volume 12 (2008) - Paper No. 7 - Page 2

\title{
R. B. Lammers, M. A. Rawlins, and C. J. Vorosmarty
}

Water Systems Analysis Group, Institute for the Study of Earth, Oceans, and Space, University of New Hampshire, Durham, New Hampshire

\section{T. S. Rupp}

Department of Forest Sciences, University of Alaska Fairbanks, Fairbanks, Alaska

\section{W. Wu}

National Center for Atmospheric Research, Boulder, Colorado

\section{Calef}

Department of Geography and Planning, University at Albany, State University of New York, Albany, New York

Received 13 June 2007; accepted 16 January 2008

\begin{abstract}
The primary goal of the Western Arctic Linkage Experiment (WALE) was to better understand uncertainties of simulated hydrologic and ecosystem dynamics of the western Arctic in the context of 1) uncertainties in the data available to drive the models and 2) different approaches to simulating regional hydrology and ecosystem dynamics. Analyses of datasets on climate available for driving hydrologic and ecosystem models within the western Arctic during the late twentieth century indicate that there are substantial differences among the mean states of datasets for temperature, precipitation, vapor pressure, and radiation variables. Among the studies that examined temporal trends among the alternative climate datasets, there is not much consensus on trends among the datasets. In contrast, monthly and interannual variations of some variables showed some correlation across the datasets. The application of hydrology models driven by alternative climate drivers revealed that the simulation of regional hydrology was sensitive to precipitation and water vapor differences among the driving datasets and that accurate simulation of regional water balance is limited by biases in the forcing data. Satellitebased analyses for the region indicate that vegetation productivity of the region increased during the last two decades of the twentieth century because of earlier spring thaw, and the temporal variability of vegetation productivity simulated by different models from 1980 to 2000 was generally consistent with estimates based on the satellite record for applications driven with alternative climate datasets. However, the magnitude of the fluxes differed by as much as a factor of 2.5 among applications driven with different climate data, and spatial patterns of temporal trends in carbon dynamics were quite different among simulations. Finally, the study identified that the simulation of fire by ecosystem models is particularly sensitive to alternative climate datasets, with little or no fire simulated for some datasets. The results of WALE identify the importance of conducting retrospective analyses prior to coupling hydrology and ecosystem models with climate system models. For applications of hydrology and
\end{abstract}


Earth Interactions • Volume 12 (2008) - Paper No. 7 • Page 3

ecosystem models driven by projections of future climate, the authors recommend a coupling strategy in which future changes from climate model simulations are superimposed on the present mean climate of the most reliable datasets of historical climate.

KEYWORDS: Arctic; Boreal; Carbon; Climate; Ecosystem models; Hydrology; WALE; Western Arctic Linkage Experiment

\section{Introduction}

Global surface air temperature has warmed substantially since the middle of the nineteenth century (Jones and Moberg 2003). This warming has been particularly strong in all latitudinal regions since about 1980 (Alley et al. 2003; Johannessen et al. 2004). Between 1970 and 2000, surface air temperature over terrestrial regions between $50^{\circ}$ and $70^{\circ} \mathrm{N}$ has increased approximately $0.35^{\circ} \mathrm{C}$ decade $^{-1}$ (McGuire et al. 2006; Euskirchen et al. 2007). The recent warming in high latitudes is affecting a broad spectrum of physical, ecological, and human/cultural systems in this region (Serreze et al. 2000; Overland et al. 2004; Stow et al. 2004; Chapin et al. 2005a; Chapin et al. 2005b; Hinzman et al. 2005; Euskirchen et al. 2006; Serreze and Francis 2006). Some of these changes may be irreversible on century time scales (e.g., sea ice, soil carbon, and thermohaline circulation), and have the potential to cause rapid changes in the Earth system by substantially influencing global water and energy balance (Curry et al. 1996; Chapin et al. 2000; McGuire and Chapin 2006; McGuire et al. 2003; McGuire et al. 2004; McGuire et al. 2006; McGuire et al. 2007).

Responses of high-latitude terrestrial ecosystems to global change have the potential to affect the Earth system through changes in 1) water and energy exchange with the atmosphere, 2 ) the exchange of radiatively active gases with the atmosphere, and 3) the delivery of freshwater to the Arctic Ocean (McGuire et al. 2006). To predict the role of high-latitude terrestrial ecosystems in the response of the Earth system to global change requires the integration of climate dynamics, ecosystem dynamics, and large-scale hydrology in high-latitude regions. The Western Arctic Linkage Experiment (WALE) Project was designed to assess the ability of models to simulate water/energy and $\mathrm{CO}_{2}$ exchange with the atmosphere, and freshwater delivery to the ocean for the Alaskan region in the 1980s and 1990s. The primary goal of WALE was to better understand uncertainties of simulated hydrologic and ecosystem dynamics of the western Arctic in the context of 1) uncertainties in the data available to drive the models and 2) different approaches to simulating regional hydrology and ecosystem dynamics. Our strategy to achieve this goal was to evaluate uncertainties in regional hydrology and carbon estimates in Alaska and the adjacent Yukon Territory associated with alternative driving datasets and alternative simulation models. Therefore, the objectives of WALE were to evaluate uncertainties among alternative driving datasets for the region, evaluate uncertainties among applications of different models using common driving data, and evaluate uncertainties in hydrologic and ecosystem models driven with different datasets. In this paper, we provide an overview of WALE and a synthesis of results from the papers in the WALE special theme of Earth Interactions. 
Earth Interactions - Volume 12 (2008) - Paper No. 7 • Page 4

\section{Design of WALE}

High-latitude terrestrial ecosystems cover approximately one-quarter of the Earth's terrestrial surface (excluding Antarctica). Modeling the role of this region in the Earth system is a complex undertaking. The representation of the interactions among climate dynamics, large-scale hydrology, and terrestrial ecosystem dynamics must consider how these interactions and dynamics vary across a broad and heterogeneous region. How do we integrate these dynamics to represent the role of high-latitude terrestrial ecosystems in the functioning of the Earth system?

It is important to carefully evaluate issues involved in coupling models that simulate climatic, hydrologic, and ecosystem dynamics of high latitudes. First, because appropriate data have not been readily available, no model has been adequately evaluated in a historical context for this broad region for a significant length of time. Therefore, models should be evaluated in retrospective analyses before coupling the models together. This is important for evaluating the long-term behavior of the models and for gaining confidence in applying the models to make future projections. Second, models should first be evaluated over a terrestrial high-latitude subregion that has substantial information on climate, hydrologic, and ecosystem dynamics.

For this study, we chose the western Arctic as the spatial domain (Figure 1) and 1981-2001 as the temporal extent of our analysis because of the substantial historical information on climatic, hydrologic, and ecosystem dynamics for the region during the last two decades of the twentieth century. The boundaries of the western Arctic in this study completely encompass the drainage basin of the Yukon River, and the region includes most of Alaska and adjacent areas in northwestern Canada. The region includes two long-term ecological research (LTER) sites: one that is focused on tundra ecosystems (Toolik Lake LTER; Hobbie et al. 1994) and another that is focused on boreal forest ecosystems (Bonanza Creek LTER; Chapin et al. 2006). The Kuparuk Flux Study (Kane and Reeburgh 1998) and the Arctic Transitions in the Land Atmosphere System Study (ATLAS; McGuire et al. 2003) have also been conducted in the western Arctic during the last two decades to understand the role of tundra ecosystems in the Earth system.

The WALE region is defined in terms of nodes of the National Snow and Ice Data Center (NSIDC) north polar Equal-Area Scalable Earth (EASE) grid (Armstrong and Brodzik 1995). The region spans a latitudinal range from approximately $55^{\circ}$ to $70^{\circ} \mathrm{N}$ and a longitudinal range from approximately $120^{\circ}$ to $165^{\circ} \mathrm{W}$, while land areas within the region comprise 3511 grid cells with nominal $25 \mathrm{~km} \times 25 \mathrm{~km}$ resolution and a total representative area of approximately 2.2 million $\mathrm{km}^{2}$ (Figure 1). Applications of models in this study considered six land-cover types over the WALE region (Figure 2): tundra, black spruce forest, white spruce forest, boreal broadleaf deciduous forest, temperate coastal conifer forest, and nonvegetation (rock and ice).

Below we summarize the results of the studies in this special theme that 1) evaluate uncertainties in driving datasets, 2) evaluate uncertainties in simulating regional hydrologic dynamics, and 3) evaluate uncertainties in simulating regional ecosystem dynamics. Based on these studies, we conclude this paper with recommendations for coupling models of climatic, hydrologic, and ecosystem dynamics. 


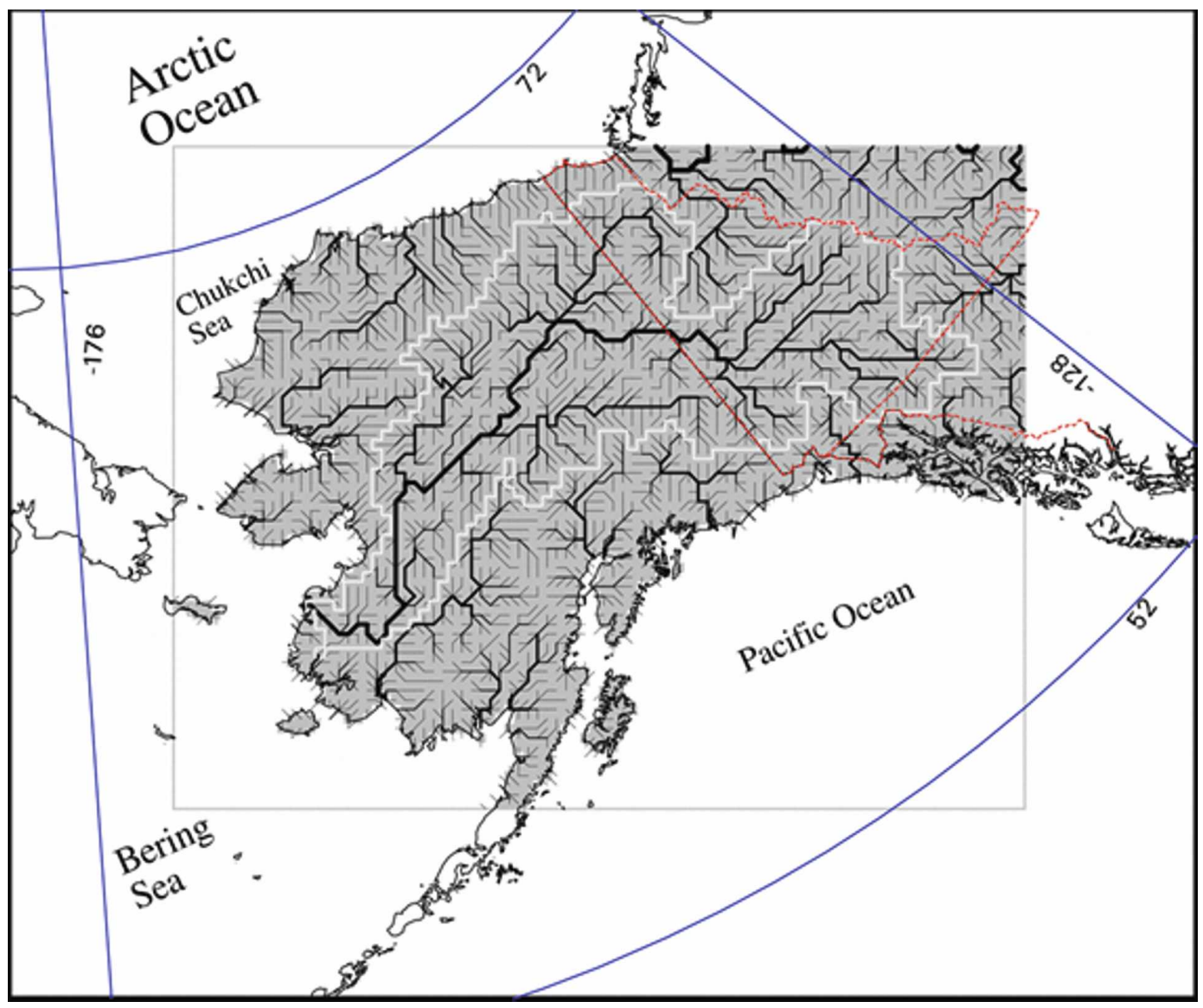

Figure 1. WALE domain (gray box) showing river network at $25-\mathrm{km}$ resolution with the drainage basin of the Yukon River outlined in white.

\section{Uncertainties among alternative driving datasets}

The three types of climate datasets that we considered for use in this study were datasets based on global-scale reanalyses, global climate datasets based on "interpolation" of surface observations, and a prognostic climate dataset based on a regional simulation of a mesoscale climate model. We organized three global reanalysis datasets at $25 \mathrm{~km} \times 25 \mathrm{~km}$ resolution for the WALE region: 1) the National Centers for Environmental Prediction-National Center for Atmospheric Research (NCEP-NCAR) reanalysis project (Kalnay et al. 1996), which we refer to as NCEP1; 2) a similar dataset for which temperature has been modified by elevation and precipitation has been modified with a statistical rescaling approach (Serreze et al. 2003), which we refer to as NCEP2 (not to be confused with NCEP II sensu; Kistler et al. 2001); and the 40-yr European Centre for Medium-Range Weather Forecasts Re-Analysis (Uppala et al. 2005), which we refer to as ERA-40. We established the NCEP1 dataset as the standard for comparing the applications of different models over the WALE region. We organized two datasets based on 


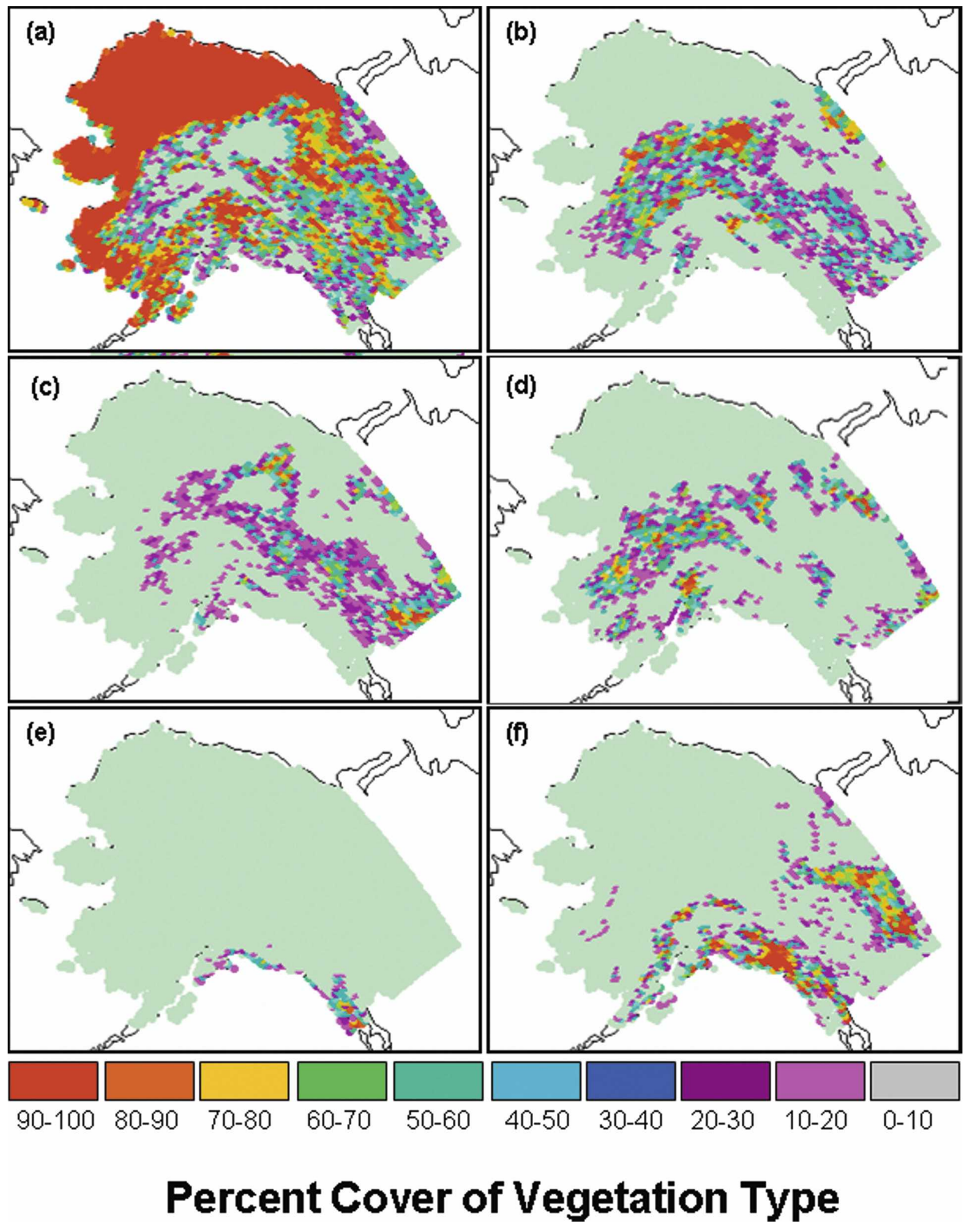

Figure 2. The fractional cover of the six different land-cover classes considered in WALE: (a) tundra, (b) black spruce forest, (c) white spruce forest, (d) boreal broadleaf deciduous forest, (e) temperate coastal conifer forest, and (f) nonvegetation (rock and ice). 
surface observations for the WALE region: 1) the Climate Research Unit/ University of East Anglia temperature dataset version 2 (CRUTEM2v; Jones et al. 2001; Mitchell and Jones 2005), which we refer to as the CRU dataset; and 2) the Willmott and Matsuura dataset (Willmott and Matsuura 1995), which we refer to as the WM dataset. The prognostic climate dataset was based on the application of the fifth-generation Pennsylvania State University-NCAR Mesoscale Model to the WALE region during the 1990s (see Wu et al. 2007); we refer to this dataset as the MM5 dataset. The climate at the boundary outside the WALE region (plus a buffer area) was prescribed in the MM5 simulations by the NCEP1 climate.

Six studies in WALE evaluated various aspects of uncertainty among climate datasets that were available to drive hydrologic and climate models over the region (Drobot et al. 2006; Rawlins et al. 2006; Clein et al. 2007; Herzfeld et al. 2007; Rupp et al. 2007; Wu et al. 2007). Drobot et al. (Drobot et al. 2006) compared the temporal and spatial variability among the temperature and precipitation variables in the NCEP1, ERA-40, CRU, WM, and MM5 datasets from 1992 to 2000 for the southern portion of the WALE region. Analysis of the climatological means of seasonal variability revealed that the largest number of differences in temperature (precipitation) occur in October (July). In contrast, interannual variability of both temperature and precipitation anomalies was correlated among the datasets. Spatial analyses revealed that June temperature (June precipitation) differs most strongly among datasets in the center (the eastern part ) of the WALE region. Analyses by Rawlins et al. (Rawlins et al. 2006) revealed that NCEP2 temperature is warmer than NCEP1 but colder than WM, and that NCEP2 precipitation is lower than NCEP1 but greater than WM. Rawlins et al. (Rawlins et al. 2006) also reported that vapor pressure estimates based on NCEP1 are substantially higher than observed vapor pressure.

Several studies examined temporal trends among the alternative climate datasets. Clein et al. (Clein et al. 2007) examined annual trends in the NCEP1, CRU, and MM5 datasets, and reported that over the WALE region between 1980 and 2000 only NCEP1 has a significant trend in mean annual temperature (a decrease of $\left.0.1{ }^{\circ} \mathrm{C} \mathrm{yr}^{-1}\right)$ and that only CRU has a significant change in annual precipitation (a decrease of $3 \mathrm{~mm} \mathrm{yr}^{-1}$ ). Over the period 1990-2000, Clein et al. (Clein et al. 2007) reported that both NCEP1 and CRU have significant changes in annual precipitation (a decrease of $9 \mathrm{~mm} \mathrm{yr}^{-1}$ ) over the WALE region. Among NCEP1, CRU, and MM5, Clein et al. (Clein et al. 2007) found no significant changes in mean annual downwelling shortwave radiation over the two decades. Two studies in WALE documented seasonal trends in climatic variables among the datasets. Kimball et al. (Kimball et al. 2007) reported that mean summer temperature (June-August) of NCEP1 increased $1.8^{\circ} \mathrm{C}$ between 1982 and 2000 . Wu et al. (Wu et al. 2007) examined trends in monthly climate variables between 1992 and 2001 among NCEP1, ERA-40, WM, and MM5. These datasets agree on increases in February temperature $\left(\sim 0.5^{\circ} \mathrm{C}\right.$ decade $\left.^{-1}\right)$ and September temperature $\left(\sim 0.4^{\circ} \mathrm{C}\right.$ decade $\left.^{-1}\right)$, and on decreases in May temperature $\left(\sim 0.2^{\circ} \mathrm{C}\right.$ decade $\left.^{-1}\right)$. Wu et al. $(\mathrm{Wu}$ et al. 2007) reported that trends in monthly precipitation over the WALE region between 1992 and 2001 differed substantially among alternative datasets. For example, the WM dataset has negative trends throughout the year, but MM5 has a large positive trend in July $\left(2 \mathrm{~mm}^{-1 a y^{-1}}\right.$ decade $\left.^{-1}\right)$ and a large negative trend in November $\left(2 \mathrm{~mm} \mathrm{day}^{-1} \mathrm{decade}^{-1}\right)$ with no trend in annual precipitation. The 
conclusion from the studies that examined temporal trends among the different climate datasets is that there is not much consensus on trends.

The studies of Wu et al. (Wu et al. 2007) and Herzfeld et al. (Herzfeld et al. 2007) were focused on a more comprehensive analysis of the temporal and spatial patterns of climate estimated in the MM5 simulation over the WALE region. Clein et al. (Clein et al. 2007) and Rupp et al. (Rupp et al. 2007) also evaluated how MM5 compared with the other climate datasets used in their studies. Surface air temperature of the MM5 simulation is generally colder in summer and generally warmer in winter than in the other climate datasets (Wu et al. 2007), with the mean state in the 1990 s generally colder by $2^{\circ}-3^{\circ} \mathrm{C}$ in comparison with other datasets (Clein et al. 2007). The mean annual precipitation of the MM5 simulation was similar to that of NCEP1, but approximately $300 \mathrm{~mm}$ more than CRU (Clein et al. 2007). However, in comparison with NCEP1 and CRU, MM5 has the highest estimates of precipitation in the winter and similar estimates to CRU in the summer. Mean annual downwelling shortwave radiation estimated by MM5 is similar to that estimated based on the CRU dataset, but is about $80 \mathrm{~W} \mathrm{~m}^{-2}$ lower than downwelling shortwave radiation estimated by the NCEP1 dataset (Clein et al. 2007). In analyzing spatiotemporal variability of the MM5 temperature and precipitation fields, Herzfeld et al. (Herzfeld et al. 2007) found more similarity between different temperature datasets and MM5 simulation results than between different precipitation datasets and MM5 simulation results. The analysis also revealed that modeling of summer precipitation fields, and to a lesser extent, summer temperature fields, appears more problematic than winter fields. Rupp et al. (Rupp et al. 2007) also documented spatial variability in the context of predicting fire activity and documented that in comparison with CRU, 20\%-40\%, depending on the year, of the WALE region was substantially wetter $(>100 \mathrm{~mm})$ in MM5, while over $90 \%$ of the WALE region was substantially colder $\left(<-2^{\circ} \mathrm{C}\right)$. In the same analysis the NCEP1 summer precipitation was substantially wetter and summer temperature was substantially colder than the CRU dataset in $40 \%-60 \%$ of the region, depending on the year.

\section{Uncertainties in simulating regional hydrology}

Rawlins et al. (Rawlins et al. 2006) evaluated hydrologic uncertainties over the WALE region by examining uncertainties associated with different climatedriving datasets and by estimating evapotranspiration in different ways. Among the three climate datasets (NCEP1, NCEP2, and WM) used to drive the Pan-Arctic Water Balance Model (PWBM; Rawlins et al. 2003), regional evapotranspiration was not very sensitive to alternative temperature and precipitation variables $(<10$ $\mathrm{mm}$ annually), but runoff was sensitive to these alternative climate variables $(>100$ $\mathrm{mm}$ annually) and appeared to be more related to precipitation variability among the datasets than to temperature variability. In contrast, both evapotranspiration and runoff calculated by the Penman-Monteith (PM) method (Monteith 1965) were similarly sensitive to alternative variables for vapor pressure (between 20and 30-mm difference annually). The study of Rawlins et al. (Rawlins et al. 2006) also documented large differences between evapotranspiration methods used by PWBM, with evapotranspiration estimated by the PM method lower by 140-160 mm annually than that estimated by the Hamon (Hamon 1963) method. The best 
result in simulating observed runoff for the Yukon River basin by PWBM, which was a mean absolute difference of $7 \%$, was achieved using the PM method in PWBM driven with either the NCEP2 or WM climate (temperature and precipitation) data. The use of NCEP1 data resulted in basinwide runoff estimates that were approximately twice the observed estimates of runoff. Thus, the accurate simulation of regional water balance is limited by biases in the forcing data.

\section{Uncertainties in simulating regional ecosystem dynamics}

Several studies in WALE examined uncertainties in simulating carbon dynamics of the region (Kimball et al. 2006; Kimball et al. 2007; Clein et al. 2007). One study used the Production Efficiency Model (PEM) to examine the sensitivity of simulated carbon dynamics to the timing of thaw over the WALE region from 1982 to 2000 (Kimball et al. 2006). In this study the PEM simulated gross primary production (GPP) and net primary production (NPP) of the WALE region based on satellite-derived estimates of the fraction of absorbed photosynthetically active radiation and NCEP1-derived estimates of air temperature, downwelling shortwave radiation, and vapor pressure deficit. Annual anomalies of GPP and NPP simulated by PEM over the WALE region were well correlated with the timing of the springtime thaw as estimated by the Special Sensor Microwave Imager.

Kimball et al. (Kimball et al. 2007) extended the study of Kimball et al. (Kimball et al. 2006) to examine how two prognostic terrestrial carbon cycle models compared with the results of PEM. The two prognostic models used in this study were the (Biogeochemical Cycles) Model BIOME-BGC and the Terrestrial Ecosystem Model (TEM). The applications of the prognostic models driven by the NCEP1 climate were generally consistent with the application of PEM in simulating a small, but widespread, positive trend in annual GPP and NPP across the WALE region between 1982 and 2000. Both of the prognostic models indicate that an increase in soil decomposition and plant-available nitrogen with regional summer warming was partially responsible for the trends in increased plant production. The prognostic models also simulated similar increases in the ratio of vegetation carbon to soil carbon storage over the two decades because of enhanced decomposition of labile organic matter in response to the temperature increase.

Clein et al. (Clein et al. 2007) conducted a study with one of the prognostic carbon cycle models, TEM, to evaluate whether the results of Kimball et al. (Kimball et al. 2007) depended on the climate dataset used to drive the model. The TEM was driven by three different climate datasets in this study: NCEP1, CRU, and MM5. Over the time period from 1980 to 2000, the interannual variability and trends of NPP were similar between simulations driven by NCEP1 and CRU. However, the study found that annual NPP and decomposition fluxes varied by as much as a factor of 2.5 among simulations driven by the different climate datasets. There was also much spatial variability in the temporal trends of NPP and decomposition across the region in simulations driven by different climates, and the spatial pattern of trends was quite different among the simulations. The study

revealed that the overall response of source/sink activity in simulations across the 
Earth Interactions - Volume 12 (2008) - Paper No. 7 • Page 10

WALE region depended substantially on the temporal trends in the climate dataset used to drive the model. For two of the three climates (NCEP1 and CRU, but not MM5), the study by Clein et al. (Clein et al. 2007) supported the conclusion of Kimball et al. (Kimball et al. 2007) that the terrestrial carbon cycle is accelerating in the WALE region with a more rapid turnover of carbon.

Fire is an important factor in the boreal forest of the WALE region, as it influences both vegetation and carbon dynamics. Rupp et al. (Rupp et al. 2007) used the Alaska Frame Based Ecosystem Code (ALFRESCO; Rupp et al. 2000) to evaluate how the simulation of fire by an ecosystem model is influenced by different climate datasets. Similar to Clein et al. (Clein et al. 2007), the study drove ALFRESCO with the NCEP1, CRU, and MM5 datasets. Among the three simulations, only the application of ALFRESCO driven by the CRU climate was able to generate a regional fire regime for the WALE region in the late twentieth century. Simulations driven by NCEP1 and MM5 produced almost no annual area burned because of substantially colder and wetter growing seasons than indicated by the CRU climate data.

\section{Summary}

Analyses of datasets on climate available for driving hydrologic and ecosystem models within the western Arctic during the late twentieth century indicate that there are substantial differences among the mean states of datasets for temperature, precipitation, vapor pressure, and radiation variables. While the application of the regional climate model MM5 to the WALE region may represent an improvement over datasets derived from global reanalyses in terms of simulating spatial variability and temporal variability in climate for the region, there were substantial biases in the mean states of some variables in the MM5 simulation. Also, among the studies that examined temporal trends among the alternative climate datasets, there is not much consensus on trends among the datasets. In contrast, the temporal anomalies of variables over the two decades were similar for some variables among the climate datasets.

The applications of hydrology and ecosystem models to the WALE region were sensitive to differences among the climate-driving datasets. The applications of PWBM driven by alternative climate drivers revealed that the simulation of regional hydrology was sensitive to precipitation and water vapor differences among the driving datasets and that accurate simulation of regional water balance is limited by biases in the forcing data. Satellite-based analyses for the region indicate that vegetation productivity of the region increased during the last two decades of the twentieth century because of earlier spring thaw, and the temporal variability of vegetation productivity simulated by the models from 1980 to 2000 was generally consistent with estimates based on the satellite record for applications driven with alternative climate datasets. However, the magnitude of the fluxes differed by as much as a factor of 2.5 among driving datasets, and spatial patterns of temporal trends in carbon dynamics were quite different among simulations. Finally, the study by Rupp et al. (Rupp et al. 2007) identified that the simulation of fire by ecosystem models is particularly sensitive to alternative climate datasets, with little or no fire simulated for some datasets.

In summary, the results of WALE identify the importance of conducting retro- 
Earth Interactions • Volume 12 (2008) • Paper No. 7 • Page 11

spective analyses prior to coupling hydrology and ecosystem models with climate system models. While there are conceptual uncertainties among the applications of different hydrology and ecosystem models (Rawlins et al. 2006; Kimball et al. 2007), uncertainties in the applications of hydrology and ecosystem models driven with different climate datasets were substantial (Rawlins et al. 2006; Clein et al. 2007; Rupp et al. 2007). This result highlights the need for improved accuracy and consistency in high-latitude climate reanalysis and other gridded meteorological data at spatial resolutions sufficient to resolve the effects of regional topography and mesoscale air masses on temperature, precipitation, atmospheric humidity, and solar radiation. The uncertainties associated with different climate datasets have implications for coupling models of terrestrial dynamics with prognostic climate models. Because the temporal anomalies of different climate datasets are often highly correlated (Drobot et al. 2006; Wu et al. 2007; Clein et al. 2007), we recommend a coupling strategy in which future changes from climate model simulations are superimposed on the present mean climate of the most reliable datasets of historical climate (Rupp et al. 2007; Clein et al. 2007). This approach has the potential to better represent the sensitivity of dynamics simulated by ecosystem models to different scenarios of future climatic change.

Acknowledgments. This research was supported by the NSF Arctic System Science Program as part of the Western Arctic Linkage Experiment (OPP-0095024, OPP0094532, 0095047, 0094958) and Fire Mediated Changes in the Arctic Project (OPP0328282). Support was also provided by the National Science Foundation through the International Arctic Research Center for the Arctic Biota/Vegetation component of the "Climate of the Arctic: Modeling and Processes" Project (OPP-0327664).

\section{References}

Alley, R. B., and Coauthors, 2003: Abrupt climate change. Science, 299, 2005-2010.

Armstrong, R. L., and M. J. Brodzik, 1995: An Earth-gridded SSM/I data set for cryospheric studies and global change monitoring. Adv. Space Res., 16, 155-163.

Chapin, F. S., III, and Coauthors, 2000: Feedbacks from arctic and boreal ecosystems to climate. Global Change Biol., 6, S211-S223.

— 657-660.

— Trends, The Millennium Ecosystem Assessment, H. Hassan, R. Scholes, and N. Ash, Eds., Island Press, 717-743.

— forest. Alaska's Changing Boreal Forest, F. S. Chapin, III, et al., Eds., Oxford University Press, 332-338.

Clein, J. S., A. D. McGuire, E. S. Euskirchen, and M. P. Calef, 2007: The effects of different climate input data sets on simulated carbon dynamics in the western Arctic. Earth Interactions, 11. [Available online at http://EarthInteractions.org.]

Curry, J. A., W. B. Rossow, D. Randall, and J. L. Schramm, 1996: Overview of Arctic cloud and radiation conditions. J. Climate, 9, 1731-1764.

Drobot, S., J. Maslanik, U. C. Herzfeld, C. Fowler, and W. Wu, 2006: Uncertainty in temperature and precipitation datasets over terrestrial regions of the western Arctic. Earth Interactions, 10. [Available online at http://EarthInteractions.org.] 


\section{Earth Interactions • Volume 12 (2008) • Paper No. 7 • Page 12}

Euskirchen, S. E., and Coauthors, 2006: Importance of recent shifts in soil thermal dynamics on growing season length, productivity, and carbon sequestration in terrestrial high-latitude ecosystems. Global Change Biol., 12, 731-750.

— A. D. McGuire, and F. S. Chapin III, 2007: Energy feedbacks to the climate system due to reduced high latitude snow cover during 20th Century warming. Global Change Biol., 13, $2425-2438$.

Hamon, W. R., 1963: Computation of direct runoff amounts from storm rainfall. Int. Assoc. Sci. Hydrol. Publ., 63, 52-62.

Herzfeld, U. C., S. Drobot, W. Wu, C. Fowler, and J. Maslanik, 2007: Spatio-temporal climate model validation: Case studies for MM5 over northwestern Canada and Alaska. Earth Interactions, 11. [Available online at http://EarthInteractions.org.]

Hinzman, L. D., and Coauthors, 2005: Evidence and implications of recent climate change in northern Alaska and other arctic regions. Climatic Change, 72, 251-298.

Hobbie, J. E., and Coauthors, 1994: Long-term measurements at the arctic LTER site. Ecological Time Series, T. M. Powell and J. H. Steele, Eds., Chapman and Hall, 391-409.

Johannessen, O. M., and Coauthors, 2004: Arctic climate change: Observed and modelled temperature and sea-ice variability. Tellus, 56A, 328-341.

Jones, P. D., and A. Moberg, 2003: Hemispheric and large scale air temperature variations: An extensive revision and an update to 2001. J. Climate, 16, 206-223.

— , T. J. Osborn, K. R. Briffa, C. K. Folland, B. Horton, L. V. Alexander, D. E. Parker, and N. A. Rayner, 2001: Adjusting for sampling density in grid-box land and ocean surface temperature time series. J. Geophys. Res., 106, 3371-3380.

Kalnay, E., and Coauthors, 1996: The NCEP/NCAR 40-Year Reanalysis Project. Bull. Amer. Meteor. Soc., 77, 437-471.

Kane, D. L., and W. S. Reeburgh, 1998: Introduction to the special section: Land-Air-IceInteractions (LAII) Flux Study. J. Geophys. Res., 103, 28 913-28 915.

Kimball, J. S., K. C. McDonald, and M. Zhao, 2006: Spring thaw and the effect on terrestrial vegetation productivity in the western Arctic observed from satellite microwave and optical remote sensing. Earth Interactions, 10. [Available online at http://EarthInteractions.org.]

— , and Coauthors, 2007: Climate driven increases in boreal and arctic vegetation productivity: Evidence of decreasing stability of the northern high latitude terrestrial carbon reservoir. Earth Interactions, 11. [Available online at http://EarthInteractions.org.]

Kistler, R., and Coauthors, 2001: The NCEP-NCAR 50-Year Reanalysis: Monthly means CDROM and documentation. Bull. Amer. Meteor. Soc., 82, 247-267.

McGuire, A. D., and F. S. Chapin III, 2006: Climate feedbacks in the Alaskan Boreal Forest. Alaska's Changing Boreal Forest, F. S. Chapin, III, et al., Eds., Oxford University Press, 309-322.

— M. Sturm, and F. S. Chapin III, 2003: Arctic Transitions in the Land-Atmosphere System (ATLAS): Background, objectives, results, and future directions. J. Geophys. Res., 108, 8166, doi:10.1029/2002JD002367.

—, M. Apps, F. S. Chapin III, R. Dargaville, and M. D. Flannigan, 2004: Land cover disturbances and feedbacks to the climate system in Canada and Alaska. Land Change Science: Observing, Monitoring, and Understanding Trajectories of Change on the Earth's Surface, G. Gutman et al., Eds., Kluwer Academic Publishers, 139-161.

—, F. S. Chapin III, J. E. Walsh, and C. Wirth, 2006: Integrated regional changes in arctic climate feedbacks: Implications for the global climate system. Annu. Rev. Environ. Resour., 31, 61-91.

— , and Coauthors, 2007: Responses of high latitude ecosystems to global change: Potential consequences for the climate system. Terrestrial Ecosystems in a Changing World, J. G. Canadell, D. E. Pataki, and L. F. Pitelka, Eds., The IGBP Series, Springer-Verlag, 297-310.

Mitchell, T. D., and P. D. Jones, 2005: An improved method of constructing a database of monthly climate observations and associated high-resolution grids. Int. J. Climatol., 25, 693-712. 


\section{Earth Interactions • Volume 12 (2008) • Paper No. 7 • Page 13}

Monteith, J. L., 1965: Evaporation and environment. The State of Movement of Water in Living Organisms, G. E. Fogg, Ed., Cambridge University Press, 205-233.

Overland, J. E., M. C. Spillane, and N. N. Soreide, 2004: Integrated analysis of physical and biological Pan-Arctic change. Climatic Change, 63, 291-322.

Rawlins, M. A., R. B. Lammers, S. Frolking, B. M. Fekete, and C. J. Vorosmarty, 2003: Simulating pan-Arctic runoff with a macro-scale terrestrial water balance model. Hydrol. Processes, 17, 2521-2539.

— S. Frolking, R. B. Lammers, and C. J. Vorosmarty, 2006: Effects of uncertainty in climate inputs on simulated evapotranspiration and runoff in the western Arctic. Earth Interactions, 10. [Available online at http://EarthInteractions.org.]

Rupp, T. S., A. M. Starfield, and F. S. Chapin III, 2000: A frame-based spatially explicit model of subarctic vegetation response to climatic change: Comparison with a point model. Landscape Ecol., 15, 383-400.

— X. Xhen, M. Olson, and A. D. McGuire, 2007: Sensitivity of simulated boreal fire dynamics to uncertainties in climate drivers. Earth Interactions, 11. [Available online at http:// EarthInteractions.org.]

Serreze, M. C., and J. A. Francis, 2006: The Arctic amplification debate. Climatic Change, 76, 241-264.

—, J. E. Walsh, F. S. Chapin III, T. Osterkamp, and M. Dyurgerov, 2000: Observational evidence of recent change in the northern high-latitude environment. Climatic Change, 46, 159-207.

—, M. P. Clark, and D. H. Bromwich, 2003: Monitoring precipitation over the arctic terrestrial drainage system: Data requirements, shortcomings, and applications of atmospheric reanalysis. J. Hydrometeor., 4, 387-407.

Stow, D., A. Hope, A. D. McGuire, D. Verbyla, and J. Gamon, 2004: Remote sensing of vegetation and land-cover changes in Arctic tundra ecosystems. Remote Sens. Environ., 89, 281-308.

Uppala, S. M., and Coauthors, 2005: The ERA-40 re-analysis. Quart. J. Roy. Meteor. Soc., 131, 2961-3012.

Willmott, C. J., and K. Matsuura, 1995: Smart interpolation of annually averaged air temperature in the United States. J. Appl. Meteor., 34, 2577-2586.

Wu, W., A. H. Lynch, S. Drobot, J. Maslanik, A. D. McGuire, and U. Herzfeld, 2007: Comparative analysis of the western Arctic surface climate among observations and model simulations. Earth Interactions, 11. [Available online at http://EarthInteractions.org.]

Earth Interactions is published jointly by the American Meteorological Society, the American Geophysical Union, and the Association of American Geographers. Permission to use figures, tables, and brief excerpts from this journal in scientific and educational works is hereby granted provided that the source is acknowledged. Any use of material in this journal that is determined to be "fair use" under Section 107 or that satisfies the conditions specified in Section 108 of the U.S. Copyright Law (17 USC, as revised by P.IL. 94-553) does not require the publishers' permission. For permission for any other form of copying, contact one of the copublishing societies. 